\title{
PENGEMBANGAN SUMBERDAYA INDUSTRI KABUPATEN SUMEDANG (STUDI KASUS INDUSTRI TAHU SUMEDANG)
}

\author{
Jodhi Mahendra, Achmad Yandy Alansyah \\ Jurusan Perencanaan Wilayah dan Kota, Fakultas Teknik, Universitas Brawijaya \\ Jl. Mayjend Haryono 167 Malang 65141 - Telp (0341)567886 \\ e-mail: jodhimahendra@student.ub.ac.id
}

\begin{abstract}
ABSTRAK
Tahu Sumedang merupakan salah satu industri yang paling strategis dan prioritas di Kabupaten Sumedang berdasarkan rencana pembangunan jangka menengah wilayah dan sektor industri. Saat ini ada beberapa masalah strategis industri tahu sumedang seperti bahan dasar tahu Sumedang adalah kedelai yang diimpor dari AS, sehingga tidak menyerap produk pertanian lokal serta adanya Rencana pembangunan jalan tol Cisumdawu yang melewati Kabupaten Sumedang membuat orang hanya melewati kota tanpa mengunjungi kota. Penelitian ini bertujuan untuk memaksimalkan sumber daya lokal berdasarkan isu-isu strategis di desa-desa yang memproduksi tahu sumedang melalui identifikasi rencana aksi untuk pengembangan sumber daya industri tahu sumedang. Untuk menganalisis data, menggunakan dua metode analisis seperti analisis sub sistem dan analisis linkage system. Hasil akhir adalah untuk mengidentifikasi rencana aksi untuk rencana pengembangan industri tahu sumedang yang mencakup rencana pengembangan produk, rencana sistem keterkaitan, dan rencana peningkatan kualitas produk.
\end{abstract}

Kata Kunci: industri, prioritas, action plan

\section{ABSTRACT}

Sumedang's tofu is one of the most strategic and priority industry in Sumedang Regency based on the regional medium-term development plan and industrial agency. In existing there are some strategic issues of sumedang's tofu industry such as basic ingredients of sumedang's tofu is soybeans imported from USA, so it doesn't absorb local agricultural product. Cisumdawu toll road plan that passes through Sumedang Regency make people only pass through the city without visiting the city. This research aims to maximize the local resources based on strategic issues in villages that produce sumedang's tofu through identify action plan for resource development sumedang's tofu industry. In this reaserch, there are five analytical methods such as subsystem analysis, linkage system analysis, potential and problem analysis, SWOT analysis and force field analysis. Final output is to identify of action plan for sumedang's tofu industry development plan which includes product development plan, linkage system plan, and product quality improvementplan.

Keywords: industry, priority, action plan

\section{PENDAHULUAN}

Industri adalah suatu kegiatan ekonomi dalam pengolahan bahan mentah dan / atau memanfaatkan sumber daya industri untuk menghasilkan barang yang memiliki nilai tambah atau manfaat lebih tinggi, termasuk jasa industri (Peraturan Pemerintah Republik Indonesia Nomor 142 Tahun 2015). Dalam Master Plan Pengembangan Industri Nasional 2015-2035, Pemerintah Indonesia memiliki visi dan misi untuk mengembangkan sektor industri di Indonesia untuk menjadi pilar dan penggerak perekonomian nasional. Pengembangan sektor industri tidak hanya untuk industri besar, tetapi juga untuk industri kecil dan rumah tangga.

Pengembangan industri ditujukan untuk semua wilayah di Indonesia, termasuk Kabupaten Sumedang. Pemerintah Kabupaten Sumedang telah mengatur beberapa program untuk meningkatkan kemampuan teknologi industri; program pengembangan industri kecil dan menengah; dan pengembangan pusat-pusat industri potensial yang terdaftar di RPJMD Kabupaten Sumedang 2014-2018. Selain itu, Pemerintah Kabupaten Sumedang menetapkan 9 industri yang diprioritaskan untuk pengembangan berdasarkan potensi yang ada, salah satunya adalah industri tahu Sumedang. Di Kabupaten Sumedang terdapat 282 industri tahu yang tersebar di seluruh Kabupaten Sumedang. Namun, ada beberapa masalah dalam pengembangan industri tahu Sumedang, seperti bahan baku untuk industri tahu Sumedang masih mengandalkan ekspor kedelai dari AS, produk tahu yang tidak tahan lama, dan rencana pembangunan jalan tol Cisumdawu yang dikhawatirkan akan mengurangi jumlah pengunjung Kabupaten Sumedang. Dengan demikian penelitian ini bertujuan untuk mengembangkan rencana strategis untuk 
pengembangan industri tahu berdasarkan potensi dan masalah yang ada.

\section{METODE PENELITIAN}

Penelitian ini menggunakan pendekatan kuantitatif dengan tujuan menyusun rencana strategis untuk pengembangan industri tahu di Kabupaten Sumedang sebagai industri prioritas. Teknik pengumpulan data yang digunakan adalah wawancara dan studi literatur. Wawancara digunakan untuk memperoleh data input, proses, dan output pada pemain industri dan lembaga terkait, sedangkan studi literatur adalah untuk mendapatkan data sekunder dari lembaga terkait. Ada beberapa teknik analisis yang digunakan untuk dapat mengembangkan rencana strategi pengembangan industri tahu, yaitu analisis subsistem dan analisis linkage system.

\section{HASIL DAN PEMBAHASAN}

Industri tahu Sumedang adalah salah satu industri prioritas di Kabupaten Sumedang. Industri ini mulai dikembangkan sejak 1917 dan menjadi kuliner khas di Kabupaten Sumedang. Industri tahu Sumedang banyak dikembangkan di Kabupaten Sumedang Selatan dan Kabupaten Sumedang Utara. Berdasarkan data dari Dinas Perindustrian dan Perdagangan Koperasi Kabupaten Sumedang, ada 282 industri tahu yang tersebar di seluruh Kabupaten Sumedang.

Modal awal yang dibutuhkan untuk membangun industri tahu Sumedang mencapai Rp. 70.000.000, dengan tenaga kerja sekitar 3 hingga 10 orang direkrut dari masyarakat setempat yang diberi upah Rp. 25.000, - dalam satu proses penggilingan. Industri tahu Sumedang juga menerima dana dari pemerintah melalui KUR dalam hal modal, di mana pemerintah menyediakan dana hingga Rp. 25.000.000, - tetapi tidak dalam bentuk uang, tetapi dalam bentuk mesin produksi dan bahan baku. Untuk membuat tahu sumedang bahan utama yang dibutuhkan adalah kedelai. Kedelai diperoleh dari Amerika Serikat dengan harga Rp 7.200 hingga Rp 7.500 per kilogram, yang dalam proses produksi tahu Sumedang membutuhkan 500 ton kedelai per bulan.

Kedelai tidak diambil dari daerah sekitarnya karena ketersediaan produksi kedelai yang tidak memenuhi kebutuhan produksi dan harga yang lebih tinggi. Produksi tahu Sumedang membutuhkan 50 hingga 100 kilogram kedelai per hari tergantung permintaan. Selain itu, air bersih diperlukan untuk proses produksi yang diperoleh dari PDAM. Alat yang dibutuhkan dalam proses produksi adalah pisau, wajan, filter, alat memasak, mesin cuci kedelai, dan mesin penggiling kedelai.

Mesin ini menggunakan bahan bakar diesel yang dibutuhkan hingga 1 liter / pabrik. Alat- alat produksi ditoleransi dari Kabupaten Sumedang. Jika tidak menggunakan bahan bakar diesel, proses produksinya menggunakan listrik dari PLN dengan daya 5.000 watt.

Proses produksi tahu sumedang terdiri dari beberapa tahap. Pertama, kedelai dicuci bersih. Kedua, kedelai kemudian digiling menjadi bubuk dan disaring untuk memilah kedelai yang tepat. Kemudian kedelai mendidih sampai matang dan disaring. Langkah terakhir adalah mencetak tahu ke dalam kotak. Limbah yang dihasilkan dari proses produksi tahu Sumedang digunakan sebagai mencuci dan merebus limbah dan limbah tahu.

Limbah cair dibuang ke saluran drainase atau sawah tanpa diproses terlebih dahulu. Sedangkan ampas tahu dijual ke Lembang, Bandung untuk dijadikan pakan ternak. Suatu saat proses produksi tahu Sumedang akan menghasilkan 5 nampan tahu dengan menggunakan $8 \mathrm{~kg}$ kedelai, sehingga dalam satu hari industri tahu Sumedang dapat memproduksi hingga 30 nampan tahu. Penentuan harga tahu Sumedang ditentukan oleh Asosiasi Tahu Sumedang, yang untuk pedagang kaki lima seharga Rp. 500,00/benih dan untuk restoran seharga Rp. 600,00/biji. Hal ini dimaksudkan agar pasar jalanan tidak kalah dengan restoran. Untuk industri kecil, omzet yang diperoleh dalam satu bulan bisa mencapai Rp 30.000.000, sedangkan untuk industri rumah tangga mencapai $\mathrm{Rp}$ 6.000.000 hingga $\mathrm{Rp} \mathrm{7.000.000} \mathrm{setiap} \mathrm{bulan.}$ Pasar untuk tahu Sumedang adalah pedagang tahu Sumedang atau dijual di kios pribadi. Tahu Sumedang yang belum digoreng bisa bertahan hingga 3 jam, sedangkan yang sudah digoreng bisa bertahan hingga 1 hari.

\section{Subsistem analisis}

Fungsi analisis sub sistem digunakan untuk melihat komponen input, proses, dan output dari industri tahu Sumedang sehingga potensi dan masalah akan ditemukan. Sub-sistem input terdiri dari modal untuk bisnis, bahan baku produksi, sumber daya industri atau pekerja, serta sumber energi yang digunakan untuk industri. Sub-sistem proses terdiri dari teknologi yang digunakan dalam produksi dan sarana dan prasarana pendukung. Sedangkan sub-sistem output terdiri dari produk yang dihasilkan, pemasaran produk, dan produk limbah industri. 
Tabel 1. Analisa Subsistem Industri Tahu

\begin{tabular}{|c|c|c|c|c|}
\hline No. & $\begin{array}{c}\text { Sub } \\
\text { Sistem }\end{array}$ & Variabel & Hasil & Analisis \\
\hline \multirow{3}{*}{1.} & \multirow{3}{*}{ Input } & Modal & $\begin{array}{l}\text { Tidak semua industri tahu } \\
\text { mendapat modal dari } \\
\text { pemerintah. Ada program } \\
\text { KUR sebesar Rp. } 25.000 .000 \\
\text { / industri dalam bentuk } \\
\text { penyediaan bahan baku. }\end{array}$ & $\begin{array}{l}\text { Potensi: } \\
\text { - Terdapat program CSR dari bank yang } \\
\text { memudahkan masyarakat dalam } \\
\text { mengembangkan usaha tahu Sumedang. } \\
\text { Masalah: } \\
\text { - Pembagian modal untuk pelaku usaha tahu } \\
\text { Sumedang yang berasal dari pemertintah } \\
\text { tidak terbagi rata }\end{array}$ \\
\hline & & Bahan Baku & $\begin{array}{l}\text { Kedelai yang digunakan untuk } \\
\text { produksi tahu masih } \\
\text { menggunakan kedelai impor } \\
\text { yang berasal dari Amerika } \\
\text { Serikat }\end{array}$ & $\begin{array}{l}\text { Potensi: } \\
\text { - Harga kedelai impor lebih murah } \\
\text { dibandingkan dengan kedelai lokal } \\
\text { sehingga dapat memberi keuntungan para } \\
\text { pelaku industri tahu Sumedang. } \\
\text { Masalah: } \\
\text { - Harga kedelai lokal lebih mahal } \\
\text { dibandingkan kedelai impor } \\
\text { Belum ada yang memenuhi kebutuhan } \\
\text { produksi } \\
\text { Tidak memberdayakan masyarakat lokal } \\
\text { apabila menggunakan bahan baku impor } \\
\text { Nilai tukar dollar yang tidak pasti } \\
\text { sehingga akan berdampak pada } \\
\text { pendapatan dan keuntungan yang } \\
\text { diperoleh pelaku usaha tahu Sumedang }\end{array}$ \\
\hline & & $\begin{array}{l}\text { Sumber Daya } \\
\text { Manusia }\end{array}$ & $\begin{array}{l}\text { Sumber daya manusia berasal } \\
\text { dari masyrakat setempat } \\
\text { dengan memberi upah Rp. } \\
15.000 \text {; / produksi }\end{array}$ & $\begin{array}{l}\text { Potensi: } \\
\text { - Tenaga kerja yang berasal dari } \\
\text { masyarakat sekitar industri merupakan } \\
\text { salah satu bentuk pemberdayaan } \\
\text { masyarakat dan mengurangi jumlah } \\
\text { pengangguran yang ada di daerah } \\
\text { sekitar. } \\
\text { - Biaya tenaga kerja yang cenderung } \\
\text { terjangkau sehingga akan mengurangi } \\
\text { biaya produksi } \\
\text { Masalah: }\end{array}$ \\
\hline \multirow[b]{2}{*}{2.} & & Teknologi & $\begin{array}{l}\text { Peralatan yang digunakan } \\
\text { sederhana dan mudah } \\
\text { diperoleh dari daerah sekitar }\end{array}$ & $\begin{array}{l}\text { Potensi: } \\
\text { - Peralatan yang digunakan masih } \\
\text { sederhana, sehingga cenderung lebih } \\
\text { murah dan mudah diperoleh } \\
\text { Masalah: } \\
\text { - }\end{array}$ \\
\hline & Proses & $\begin{array}{l}\text { Fasilitas } \\
\text { Pendukung dan } \\
\text { Infrastruktur }\end{array}$ & $\begin{array}{l}\text { Listrik yang } \\
\text { digunakan dalam } \\
\text { produksi tahu } \\
\text { Sumedang dipasok } \\
\text { oleh PLN dan juga } \\
\text { menggunakan dinamo } \\
\text { berbahan bakar diesel } \\
\text { Sumber air bersih } \\
\text { berasal dari PDAM } \\
\text { atau sumur pribadi }\end{array}$ & $\begin{array}{l}\text { Potensi: } \\
\text { - Tidak ada permasalahan dalam sumber } \\
\text { daya listrik ataupun sumber air bersih } \\
\text { Masalah: } \\
\text { - Tidak adanya saluran pembuangan } \\
\text { khusus untuk limbah produksi dapat } \\
\text { berpotensi mencemari lingkungan }\end{array}$ \\
\hline 3. & Output & Produk & $\begin{array}{l}\text { - Jumlah hasil produksi } \\
\text { tahu Sumedang } \\
\text { mencapai } 30 \text { loyang } \\
\text { tahu / hari dan bisa } \\
\text { meningkat atau } \\
\text { menurun tergantung } \\
\text { dari jumlah } \\
\text { permintaan. } \\
\text { Produk tahu yang } \\
\text { masih mentah dapat }\end{array}$ & $\begin{array}{l}\text { Potensi: } \\
\text { - Produk tidak menggunakan bahan } \\
\text { pengawet sehingga aman untuk } \\
\text { dikonsumsi. } \\
\text { Masalah: } \\
\text { - Produk tidak tahan lama sehingga sulit } \\
\text { untuk dipasarkan ke luar kota karena } \\
\text { tidak menggunakan bahan pengawet } \\
\text { dan tidak memliki kemasan khusus. }\end{array}$ \\
\hline
\end{tabular}




\begin{tabular}{|c|c|c|c|c|}
\hline No. & $\begin{array}{c}\text { Sub } \\
\text { Sistem } \\
\end{array}$ & Variabel & Hasil & Analisis \\
\hline & & & $\begin{array}{l}\text { bertahan selama } 3 \\
\text { jam, sedangkan tahu } \\
\text { yang telah digoreng } \\
\text { dapat bertahan } \\
\text { hingga } 1 \text { hari. } \\
\end{array}$ & \\
\hline & & Pemasaran & $\begin{array}{l}\text { Beberapa pelaku industri tahu } \\
\text { Sumedang memasarkan hasil } \\
\text { produksinya di warung atau } \\
\text { restoran miliknya sendiri dan } \\
\text { mendistribusikan ke pedagang } \\
\text { kaki lima. }\end{array}$ & $\begin{array}{l}\text { Potensi: } \\
\text { - Penjualan tahu di Kabupaten Sumedang } \\
\text { Menjadikan tahu Sumedang sebagai } \\
\text { salah satu kuliner yang dicari oleh } \\
\text { wisatawan atau pengunjung. } \\
\text { Masalah: } \\
\text { - Karena produk tahu Sumedang tidak } \\
\text { tahan lama, ada kesulitan dalam } \\
\text { memasarkannya ke luar Kabupaten } \\
\text { Sumedang }\end{array}$ \\
\hline & & Limbah & $\begin{array}{l}\text { Limbah yang dihasilkan } \\
\text { berupa limbah ampas tahu } \\
\text { dan air sisa mencuci dan air } \\
\text { sisa rebusan tahu. }\end{array}$ & $\begin{array}{l}\text { Potensi: } \\
\text { - Limbah sisa produksi tahu sudah diolah } \\
\text { menjadi biogas atau dijual ke daerah } \\
\text { Lembang,Bandung untuk dijadikan } \\
\text { pakan ternak. } \\
\text { Masalah: } \\
\text { - Air limbah sisa produksi dibuang ke } \\
\text { saluran drainase tanpa ada saluran khusus } \\
\text { sehingga berpotensi menjadi pencemar. }\end{array}$ \\
\hline
\end{tabular}

\section{Linkage System}

Analisis linkage system dibagi dua jenis yaitu backward linkage dan forward linkage. Industri tahu Sumedang tersebar di hampir

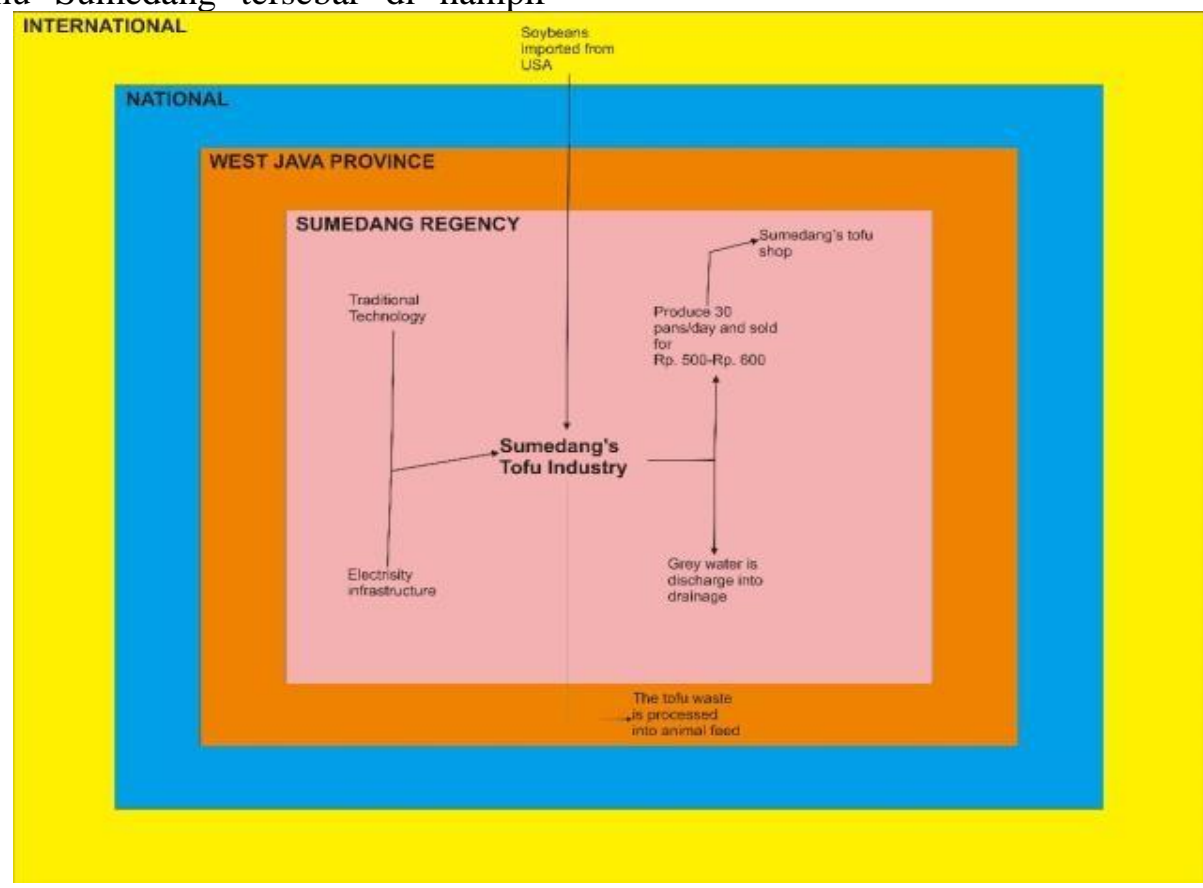

Gambar 1. Analisis Linkage System

Kedelai yang diimpor dari AS membuat komoditas kedelai lokal tidak mampu memenuhi kebutuhan produksi tahu sumedang. Harga jual impor dianggap kedelai lokal. Pengembangan komoditas pertanian sangat semua desa di Kabupaten Sumedang. Hanya saja sebagian besar desa di Kabupaten Sumedang Utara dan Kabupaten Sumedang Selatan. 


\section{Force Field Anlysis}

Faktor kunci keberhasilan merupakan faktor yang memiliki total nilai bobot (TNB) terbesar diantara faktor-faktor yang berpengaruh terhadap sektor industri. Dari tiap faktor pendorong dan faktor penghambat, dipilih masing-masing 4 nilai terbesar. Berikut merupakan FKK dari sektor industri Kabupaten Sumedang.

Tabel 2. Faktor Kunci Pendorong dan Penghambat Sektor Industri

\begin{tabular}{|c|c|c|c|c|c|c|}
\hline No. & NB & Faktor Kunci Pendorong & No. & NB & $\mathbf{T}$ & Faktor Kunci Penghambat \\
\hline 1. & .42 & $\begin{array}{l}\text { Tahu Sumedang merupakan } \\
\text { produk kuliner identitas } \\
\text { dari } \\
\text { Kabupaten Sumedang }\end{array}$ & & 92 & 1. & $\begin{array}{l}\text { Belum ada inovasi dalam } \\
\text { pengemasan }\end{array}$ \\
\hline 2. & .31 & $\begin{array}{l}\text { Sudah ada pengolahan } \\
\text { limbah ampas tahu menjadi } \\
\text { biogas }\end{array}$ & & 72 & 1. & $\begin{array}{l}\text { Produk tahu tidak tahan lama } \\
\text { sehingga sulit untuk } \\
\text { dieksport }\end{array}$ \\
\hline 3. & .92 & $\begin{array}{l}\text { Adanya peternakan lele yang } \\
\text { membutuhkan ampas tahu } \\
\text { sebagai } \\
\text { pakan ternak }\end{array}$ & & 62 & 1. & $\begin{array}{l}\text { Industri tahu Sumedang } \\
\text { bergantung pada import kedelai } \\
\text { dari USA }\end{array}$ \\
\hline 4. & .88 & $\begin{array}{l}\text { Adanya lembaga Pertasum } \\
\text { yang menaungi industry tahu } \\
\text { Sumedang }\end{array}$ & & 12 & 1. & $\begin{array}{l}\text { Belum ada inovasi dalam variasi } \\
\text { produk }\end{array}$ \\
\hline
\end{tabular}

Sumber: Hasil Analisis, 2019

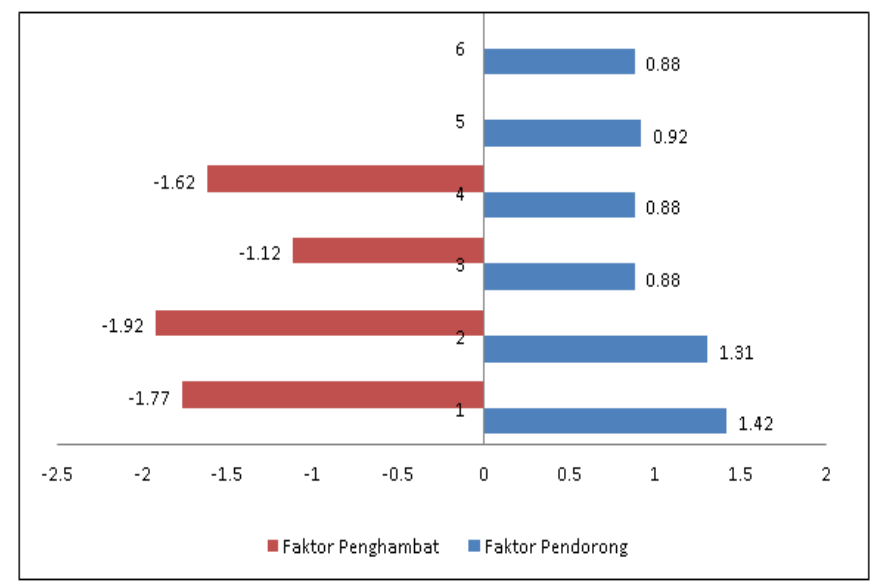

Gambar 2. Diagram Medan Kekuatan

Sumber: Hasil Analisis, 2019

\section{Visi dan Misi}

Perumusan visi merupakan penggabungan hasil faktor kunci pendorong dan faktor kunci penghambat dan didasarkan pada faktor kunci pendorong yang dapat diandalkan untuk menghilangkan maupun meminimalisasi dampak dari faktor kunci penghambat. Pada penyusunan misi, didapat dengan menggabungkan faktor pendorong dan penghambat yang memiliki keterkaitan yang paling erat. Penyusunan misi diarahkan pada pengoptimalan faktor pendorong kunci untuk mengatasi atau memperbaiki faktor penghambat kunci.

Tabel 3. Visi, Misi, dan Action Plan

\begin{tabular}{|c|c|c|c|}
\hline Visi & Misi & Strategi & Action Plan \\
\hline $\begin{array}{l}\text { Mewujudkan Kabupaten } \\
\text { Sumedang menjadi sentra } \\
\text { Eko- Industri berbasis } \\
\text { IPTEK dengan } \\
\text { memanfaatkan keunggula } \\
\text { n sumber daya lokal }\end{array}$ & $\begin{array}{l}\text { Mengembangkan } \\
\text { tahu sumedang } \\
\text { menjadi city } \\
\text { branding Kabupaten } \\
\text { Sumedang }\end{array}$ & $\begin{array}{l}\text { Membangun ornamen } \\
\text { jalan dan signage pada } \\
\text { jalan utama Kabupaten } \\
\text { Sumedang }\end{array}$ & $\begin{array}{l}\text { - Membangun ornamen jalan yang } \\
\text { menggamb arkan citra Kabupaten } \\
\text { Sumedang sebagai kota tahu pada jalan } \\
\text { utama. } \\
\text { - Membangun monumen tahu } \\
\text { Sumedang pada titik masuk Kota } \\
\text { Sumedang. } \\
\text { - Memperbanyak signage menuju sentra } \\
\text { tahu Sumedang }\end{array}$ \\
\hline
\end{tabular}




\begin{tabular}{|c|c|c|c|}
\hline Visi & Misi & Strategi & Action Plan \\
\hline & & $\begin{array}{l}\text { Melakukan } \\
\text { perluasan promosi dan } \\
\text { pemasaran tahu } \\
\text { Sumedang baik secara } \\
\text { offline dan online yang } \\
\text { menjadi ciri khas } \\
\text { Kabupaten Sumedang }\end{array}$ & $\begin{array}{l}\text { - Melakukan perluasan promosi dan } \\
\text { pemasaran tahu Sumedang baik secara } \\
\text { offline dan online yang menjadi ciri } \\
\text { khas Kabupaten Sumedang ke berbagai } \\
\text { daerah. } \\
\text { - Membuka outlet tahu Sumedang pada } \\
\text { rest area jalan tol yang menuju } \\
\text { Kabupaten Sumedang dan daerah- } \\
\text { daerah sekitar Kabupaten Sumedang. } \\
\text { - Membuka outlet tahu Sumedang di } \\
\text { destinasi wisata untuk memperke } \\
\text { nalkan tahu Sumedang sebagai oleh- } \\
\text { oleh khas Kabupaten Sumedang }\end{array}$ \\
\hline & \multirow{4}{*}{$\begin{array}{l}\text { Mengembangkan } \\
\text { pengolahan tahu } \\
\text { Sumedang dari hulu } \\
\text { sampai hilir }\end{array}$} & $\begin{array}{l}\text { Mencari supplier } \\
\text { kacang } \\
\text { kedelai lokal pada } \\
\text { tingkat nasional }\end{array}$ & $\begin{array}{l}\text { - Melakukan kerjasama dengan Dinas } \\
\text { Pertanian dan petani kedelai lokal } \\
\text { untuk menjadi supplier bahan baku } \\
\text { tahu Sumedang }\end{array}$ \\
\hline & & $\begin{array}{l}\text { Menerapkan teknologi } \\
\text { ramah lingkungan }\end{array}$ & $\begin{array}{l}\text { - Menerapkan teknologi ramah } \\
\text { lingkungan pada industri tahu } \\
\text { Sumedang } \\
\text { - Melakukan pengolahan pada limbah } \\
\text { yang dihasilkan menjadi biogas dan } \\
\text { pakan ternak lele }\end{array}$ \\
\hline & & $\begin{array}{l}\text { Melakukan inovasi pada } \\
\text { produk }\end{array}$ & $\begin{array}{l}\text { - Melakukan peningkatan kualitas tahu } \\
\text { - Melakukan inovasi pengemasan tahu } \\
\text { Sumedang } \\
\text { - Melakukan inovasi variasi produk tahu } \\
\text { Sumedang }\end{array}$ \\
\hline & & $\begin{array}{l}\text { Mengembangkan sarana } \\
\text { dan prasarana yang } \\
\text { menunjang industri tahu } \\
\text { Sumedang }\end{array}$ & $\begin{array}{l}\text { - Pembangunan outlet produk tahu } \\
\text { Sumedang pada rest area } \\
\text { - Pembangun an outlet produk tahu } \\
\text { Sumedang pada destinasi wisata di } \\
\text { Kabupaten Sumedang } \\
\text { - Pembangun an kantor Pertasum dan } \\
\text { balai pelatihan } \\
\text { - Pembangunan pusat pengolahan } \\
\text { limbah industri tahu } \\
\text { - Peremajaan jalan } \\
\end{array}$ \\
\hline & $\begin{array}{l}\text { Mengembangkan } \\
\text { teknologi tepat guna } \\
\text { dalam pengolahan } \\
\text { tahu sumedang }\end{array}$ & $\begin{array}{l}\text { Menerapkan teknologi } \\
\text { yang ramah lingkungan } \\
\text { dan memanfaat kan } \\
\text { SDM maupun SDA } \\
\text { lokal }\end{array}$ & $\begin{array}{l}\text { - Menerapkan teknologi dengan } \\
\text { memanfaatkan tenaga listrik yang } \\
\text { berasal dari hasil biogas ampas tahu. } \\
\text { - Menerapkan teknologi yang tidak } \\
\text { mencemari lingkungan } \\
\text { - Memberdayakan industri lokal dalam } \\
\text { memproduksi peralatan industri tahu } \\
\text { Sumedang. } \\
\text { - Memberdayakan masyarakat sekitar } \\
\text { lokasi industri sebagai pekerja industri } \\
\text { tahu Sumedang }\end{array}$ \\
\hline & $\begin{array}{l}\text { Mengembangkan } \\
\text { pengolahan limbah } \\
\text { yang ramah } \\
\text { lingkungan }\end{array}$ & $\begin{array}{l}\text { Membangun pusat } \\
\text { pengolahan limbah }\end{array}$ & $\begin{array}{l}\text { - Membangun pusat pengolahan limbah } \\
\text { biogas dan pakan ternak serta bekerja } \\
\text { sama dengan sektor minapolitan }\end{array}$ \\
\hline
\end{tabular}

\section{KESIMPULAN}

Berdasarkan pembahasan diatas dapat disimpulkan bahwa diperlukan kolaborasi antara Dinas Pertanian dengan petani kedelai di Kabupaten Sumedang mengenai pasokan kedelai lokal sebagai bahan utama dalam Tahu Sumedang. Kerjasama antara agensi pertanian difokuskan pada pengadaan program penanaman kedelai di Indonesia (sudah ada dan direncanakan) dan digunakan sebagai pemasok kedelai untuk industri tahu di Kabupaten Sumedang. Kerja sama ini akan dapat mengurangi atau menghentikan aktivitas mengimpor kedelai dari Amerika. Dengan kolaborasi antara layanan pertanian dan petani kedelai di Indonesia, diharapkan dapat memaksimalkan hasil produksi tahu sumedang dan membantu meningkatkan pendapatan ekonomi nasional.

Di samping itu, diperlukan pula peningkatan pemberdayaan masyarakat di sekitar 
Kabupaten Sumedang sebagai tenaga kerja industri. Pemberdayaan masyarakat dapat berupa pelatihan sistem pasar hingga pelatihan inovasi produksi tahu agar lebih tahan lama. Hal ini dapat mempengaruhi proses pemasaran (ekspansi pasar) dan dapat meningkatkan pendapatan ekonomi daerah di Kabupaten Sumedang.

Industri tahu sumedang juga dapat memberikan efek keterkaitan ke depan dan keterkaitan ke belakang karena limbah dari pengolahan tahu dijual kepada petani lele di Kabupaten Sumedang. Selain itu, efek keterkaitan ke depan yang dihasilkan dari industri tahu Sumedang ke sektor pariwisata terkait dengan sesuatu untuk dibeli untuk tujuan wisata yang ditemukan di Kabupaten Sumedang.

Oleh karena itu, penyusunan rencana aksi diharapkan dapat memberi nilai tambah pada penjualan tahu sumedang sehingga dapat meningkatkan kesejahteraan masyarakat.

\section{DAFTAR PUSTAKA}

Alimudin, Arasy. (2017). Analisis Pencapaian Strategi Menggunakan Balanced Scorecard. Jurnal Pendidikan Ekonomi \& Bisnis, 5 (2): 194-205. Surabaya: Universitas Narotama

Lewin, 1951. Field Theory in Social Science. New York: Harper and Row.

Peraturan Daerah Kabupaten Sumedang Nomor 1 Tahun 2014 Rencana Pembangunan Jangka Menengah Daerah Kabupaten Sumedang Tahun 2014-2018. Sumedang.

Peraturan Pemerintah Republik Indonesia Nomor 14 Tahun 2015 Rencana Induk Pembangunan Industri Nasional 2015 2035. Juni 2015. Jakarta.

Peraturan Pemerintah Republik Indonesia Nomor 145 Tahun 2015 Kawasan Industri. Desember 2015. Jakarta.

Rustiadi, 2009. Perencanaan Dan Pengembangan Wilayah. Jakarta: Crestpent Press dan Yayasan Obor Indonesia. 
